The Geneva Papers on Risk and Insurance, 23 (No. 87, April 1998), 182-195

\title{
Long Tail Risks and Endogenous Liabilitites: Regulating Looting
}

\author{
by Timothy Swanson* and Robin Mason**
}

\section{Introduction}

In an earlier article in this journal (Mason and Swanson 1996) we argued that one of the primary causes of long tail insurance risks was the system of incentives for strategic liquidation inherent within a limited liability system. In effect limited liability makes available a loophole for the appropriation of societal rents by appropriately structured firms. This argument was based upon the previous analysis of the American savings and loan crisis undertaken by Akerlof and Romer (1993) in which they stylised the use of strategic bankruptcy for the appropriation of rents as "looting". In that earlier paper we extended and generalised their analysis, and identified the structure of firms that would make the "looting strategy" available. In this paper our objective is to set forth our conclusions from this previous analysis regarding the appropriate means of regulation of firms structured in a manner to make available the possibility of strategic liquidation. That is, we are addressing the question: How does a society regulate for looting?

Looting is a phenomenon with which most people are now familiar. It has taken two very noticeable forms recently. In the US, the thrifts crisis has been estimated to have generated societal losses in the amount of US\$140 billion. According to Akerlof and Romer, this crisis resulted from the deliberate relaxation of the regulation system regarding the savings and loan industry when a slowdown in the housing market was causing concern about the viability of some sectors of this industry. The regulators reduced reserves requirements and relaxed monitoring, and this then produced the loophole

* School of Public Policy, University College London and CSERGE.

** Department of Applied Economics, Cambridge, University. 
through which the looting strategy was able to operate. Another example of the same phenomenon occurred on a much more widespread basis in the form of the toxic waste disposal site problem. This is now a worldwide problem occasioned by the almost complete absence of any regulatory system regarding the disposal of toxic wastes prior to the $1980 \mathrm{~s}$. In this regulatory context, an obvious loophole existed whereby firms were established for the single purpose of providing landfill sites for the disposal of problematic wastes. These firms often existed with few assets other than the land on which the disposal occurred. After years of dumping, and before detection of any leakage, the firm would then dissolve its corporation and disappear, leaving others to incur the deferred costliness of its operations. The US has expended more than US\$100 billion on the cleanup operations associated with this problem (Menell 1991), and the problem of "orphaned waste sites" is prevalent within the European Union as well.

This is the essence of looting: Operation of a firm in a context in which it is possible to incur benefits today while postponing the associated costliness until some time in the future, with dissolution and liquidation occurring in the interim. The necessary conditions for looting are therefore: a) the availability of limited liability; b) the capacity to create deferred costliness; and c) the structure that renders liquidation the optimal strategy to pursue. Limited liability is of course readily available (at a small fee for legal expenses and filing) to every enterprise in western society. Deferred costliness is possible whenever damages take time to accumulate or detect, such as in the case of leaching chemicals. Environmental resources are natural locations for looting to occur, because the monitoring of common resources is often very difficult or very lax, but the US savings and loan crisis demonstrates that it is able to occur wherever monitoring is difficult or (in that instance) lax.

In short, the problem of long tail liabilities is to some extent a problem of endogenously created risks, i.e. the creation of long term deferred liabilities expressly for the purpose of avoiding them. It is a case of "extreme moral hazard" in the face of the limited liability loophole afforded by society by their laws of incorporation. Limited liability constitutes societally provided insurance for enterprises, in the absence of a premium. Some of those insured will see the benefits to be had from exploiting the underpriced policy, and this is when looting occurs. When this is the case, we are dealing with a situation that is at the boundary of the public/private interface. Although insurors are able to provide monitoring and rate adjustments for all sorts of situations (even including the "bail bonding" of suspected criminals), there is a clear public role for the state to intervene to monitor for behaviour that is, firstly, generated by its own lax system of insurance (laws of corporation) and, secondly, generating only negative social values. Looting behaviour is no more a matter for private insurance markets than is any other form of theft, and it calls for the sorts of public intervention that these other forms of rent seeking behaviour command.

This article recounts the conditions under which looting will occur in section 2 .

Then in section 3 it develops our policy recommendations for the regulation of this loophole. Section 4 concludes with some of our general ideas about the public/private interface in insurance, and how long tail risks fit into this framework. 


\section{Conditions for looting}

This section will reprise our findings from our previous article on the choice of liquidation and accumulating liabilities. In that paper we developed the conditions under which looting will occur. The primary findings were that looting is the optimal strategy whenever the firm is structured so that its revenues are frontloaded and its costs backloaded, with the costliness of exit from the industry low relative to its early benefits. The costliness of exit is made up of two primary factors: 1) the costs of liquidating sunk capital; and 2) the opportunity costs of forgoing further involvement in the industry ${ }^{1}$. A firm with a relatively labour intensive structure and an easily liquidated capital stock is the typical candidate for looting behaviour. This result has been reported in work undertaken by others as well. (Ringleb and Wiggins 1990).

The fundamental results of that paper are reported in section 3 , stating the condition under which looting is the optimal strategy from the perspective of the individual enterprise. (We report the results without substantial explanation here, and refer the interested reader back to our earlier paper). In brief, the model concerns the firm's choice of initial capital stock $\left(\mathrm{K}_{0}\right)$ at cost $\omega$,and the choice of the amount of capital to scrap in the next period $\left(K_{1}\right)$ at price $\phi_{1}$, taking these benefits as dividends $(\Delta)$, as opposed to continuing to use the capital in production in the enterprise, returning a future flow of revenue $f\left(K_{0}-K_{1}\right)$. Given the conditions in which looting occurs, there must also be the prospect of future damages (D) occurring with probability $P(E)$ where $E$ is the amount of costly effort which the firm expends on preventive measures.

The objective of the limited liability firm is therefore to maximise its value given these choices:

$$
\begin{aligned}
& V^{\mathrm{LL}}=\max _{\left\{K_{0}, K_{1}, \Delta_{1}, E\right\}}-\omega K_{0}+\frac{\Delta_{1}}{\delta_{1}}+\frac{\mathrm{E}\left[\Delta_{2}\right]}{\delta_{1} \delta_{2}} \\
& \Delta_{1}+E \leqslant f_{1}\left(K_{0}\right)+\phi_{1}\left(K_{1}\right) \\
& \Delta_{2}=\max \left[0, f_{2}\left(K_{0}-K_{1}\right)+\delta_{2}\left(f_{1}\left(K_{0}\right)+\phi_{1}\left(K_{1}\right)-\Delta_{1}-E\right)-D+\frac{\sum_{\mathrm{t}=3}^{\infty} f_{\mathrm{t}}\left(K_{0}-K_{1}\right)}{\prod_{\mathrm{t}=3}^{\infty} \delta_{t}}\right] \\
& \Delta_{2}=f_{2}\left(K_{0}-K_{1}\right)+\delta_{2}\left(f_{1}\left(K_{0}\right)+\phi_{1}\left(K_{1}\right)-\Delta_{1}-E\right)+\frac{\sum_{\mathrm{t}=3}^{\infty} f_{t}\left(K_{0}-K_{\mathrm{l}}\right)}{\prod_{\mathrm{t}=3}^{\infty} \delta_{t}} \quad \text { w.p. }(1-\mathrm{p}(\mathrm{E})) \text {. }
\end{aligned}
$$

The meaning of this equation is simple. It states that the firm has its potential liability bounded at 0 by reason of the existence of the limited liability loophole afforded by the laws of incorporation. The enterprise is effectively fully insured for any costs that are incurred in excess of the assets existing within the enterprise during that period. The firm will take the extreme nature of this constraint into consideration in the course of choosing its capital structure.

\footnotetext{
1 Obviously, this opportunity cost is necessary because a strategy of cost avoidance will not allow for the possibility of reentering the same industry under a new corporate entity; hence, the looting strategy requires that the exit from the industry be permanent from the perspective of the individual enterprise.
} 
One set of commentators have discussed this problem as a case of "judgement proofness": the impact of such free insurance on the choice of the level of capital stock with which to commence operations. Shavell (1986) argued intuitively that this free insurance would act as a subsidy, increasing the amount of capital employed within the industries with higher risks; in essence, he argued that the subsidy would generate excessive risk taking by limited liability corporations. We and others have shown, however, that the insurance subsidy has counteracting effects. In addition to the reduced prospect of feeling the full effects of the potential damages, there are also effectively reduced costs of care expenditures and effectively increased costs of capital. The overall effect of limited liability on ongoing enterprises is ambiguous, an empirical matter determined by the relative size of these various effects. (Beard, 1990; Posey 1993). For insurance purposes, it is probable that effective insurance coverage could be afforded to the various firms influenced by these incentives, so long as the insurors were able to recognise the various factors which determine these firms specific reaction to the liability system and include them in their coverage.

The problem that we address is very different from the judgement proof problem. It concerns the range of most extreme responses to the availability of societal supplied insurance: the bounded liability within the objective function set forth above. In certain cases the firms involved will not simply have incentives to undertake more risk preferring sorts of behaviour; they will in fact structure their corporations for the single purpose of planned liquidation. In these cases there are no exogenous risks. The risks created and avoided by the firm, and insured by society under limited liability, are entirely endogenous. The firm is creating them on a deferred basis for the purpose of receiving immediate benefits, while avoiding them through liquidation in the interim. This is precisely the nature of the problem that has existed in the context of the toxic waste disposal industry: extreme moral hazard (endogenous risk creation) in the face of unregulated and unpriced insurance provided by society.

It is possible to identify the nature of the industries which will produce this looting behaviour. These firms will perceive the benefits from one period's production, scrapping and liquidation as being in excess of the benefits from ongoing involvement in the industry. This condition is stated more precisely below:

CASE 1 ("Looting"): Maximum value can be extracted from the firm, by running it for 1 period, and scrapping it entirely at $t=1$; i.e.:

$$
\max _{\left\{K_{0}\right\}} \frac{f_{1}\left(K_{0}\right)+\phi_{1}\left(K_{0}\right)}{\delta_{1}}>\max _{\left\{K_{0}, K_{1}, E\right\}} \frac{f_{2}\left(K_{0}-K_{1}\right)+\delta_{2}\left(f_{1}\left(K_{0}\right)-E\right)+\frac{\sum_{\mathrm{t}=3}^{\infty} f_{t}\left(K_{0}-K_{1}\right)}{\prod_{\mathrm{t}=3}^{\infty} \delta_{t}}}{(1 .)}
$$

Where this condition holds, the choices of the firm's capital structure render future risks and liquidation prospects endogenous. The firm is now choosing to create a relatively thin capital structure made up of relatively liquid assets for the purpose of implementing a "hit and run" sort of strategy. The firm is operating with the single purpose of becoming bankrupt in the next period in order to avoid the losses it will create. This is what Akerlof and Romer termed "looting": 
... the normal economics of maximising economic value is replaced by the topsy turvy economics of maximising current extractable value, which tends to drive the firm's economic net worth deeply negative. ... Because of (the) large disparity between what the owners can capture and the losses that they create, we refer to bankruptcy for profit as looting (Akerlof and Romer 1993, p 2-3).

This is the case which requires fairly complex and carefully constructed forms of regulation. For example, private insurance markets must fail in this context. In the first instance, there is no reason for a firm planning a liquidation strategy to acquire insurance to cover its post-operational phase. Once liquidation is complete, the firm itself and the people previously involved have no reason to be concerned with any matters beyond this point in time. This is (at least at present) implicit within the meaning of the liquidation of assets and liabilities. Secondly, even though insurors have been required to continue their coverage beyond the period of liquidation under acts-based coverage, there is no possibility for insurors to regulate for or charge for endogenously created risks. Whatever the premium charged by the insurors for current coverage (based upon historical data), the firm is able to create larger losses. This is the meaning of endogenous liquidation. The firm adjusts its strategy to fit the available loophole. Shifting the responsibility for the extreme moral hazard occasioned by the limited liability loophole onto the insurance industry merely shifts the conduit through which these looting-based societal losses will flow. Ultimately these losses will be spread across society, in the form of endogenously generated and uncompensated environmental risks and also failed insurors of those risks.

Before proceeding to the policy analysis of the problem of endogenous liquidation, we will first reprise the precise set of conditions under which these problems will occur. The problem of regulating for this loophole comes down to the problem of regulating these sorts of industries. The first step in this enquiry must be the identification of the set of conditions which will define the problematic industries.

\section{Regulating for looting behaviour: necessary conditions}

Defining the problematic industries is not difficult. These are industries in which a "hit and run" sort of strategy is likely to be effective. They are therefore typified by modest amounts of relatively liquid capital stocks, operating in areas with high potential for societal damages. Chemical waste disposal now seems like an obvious case in point, with the benefit of hindsight, but it is also possible to see how it might have been identified before the fact. The time required for chemical leachage into groundwater provides for the initial requirement, while the capacity to provide disposal facilities with nothing more than a short term lease on agricultural land provided the remainder. These sorts of industries will be generated by the limited liability insurance subsidy, if they are not otherwise regulated. The key facets of these industries are: the relatively low long term productivity of capital stocks (and hence low opportunity costs of exit from the industry); the relatively high scrap value of capital (and hence low explicit costs of exit); and, the relatively high costs of cost avoidance (rendering the choice of liquidation relatively preferable).

\subsection{The importance of fixed capital investments}

Capital productivity measures the returns that can be generated from a stock of capital. Its relevance is two-fold. First, it is a major determinant of the returns to remaining 
within an industry (as opposed to liquidating early). Secondly, it measures the extent to which firms will invest in fixed, rather than mobile forms of capital; this in turn influences the relative attractiveness of the judgement proof strategy (see Wiggins and Ringleb (1992)). We will identify three regions of interest regarding firm structures, the third of which corresponds to the conditions which we are interested in regulating. These three regions refer to the capital structure: the socially optimal objective $\left(\mathrm{V}^{S O}\right)$; the judgement proof objective $\left(\mathrm{V}^{L L}\right)$; or the looting objective $\left(\mathrm{V}^{L}\right)$.

A firm that operates in region I will make its choices in a socially optimal fashion despite the availability of limited liability ( $\mathrm{V}^{S O}>\mathrm{V}^{L L}$ ). This is most likely to be the case when capital productivity is high (other things being equal). In this case, the industry will be capital intensive, generating high returns on that capital. This results in the vesting of the firm within the industry, since its return from maintaining its current capital stock operational is far greater than the return from liquidating to avoid prospective liabilities. This corporation will therefore be willing to provide for future - even substantial liabilities in order to remain in operation. An example of such an industry is petroleum extraction and transport. Companies in this industry achieve high levels of productivity and returns only by operating with massive capital investments (e.g. rigs and tankers). Equally, these capital investments are capable of generating substantial future liabilities - the Exxon Valdez incident is indicative of the scale of the liabilities that potentially can flow from these investments. The industry's response to these potential liabilities has not been to exit. Instead, all of the firms in the business of large scale extraction and transport have formed a syndicate to spread their risks across the entire industry. This insurance agreement is indicative of their commitment to the industry.

A firm that operates within region II ( $\mathrm{V}^{S O}>0$, but $\left.\mathrm{V}^{\mathrm{L}}>\mathrm{V}^{S O}\right)$ is a societally beneficial concern with a structure that presents the temptation for looting; firms in this region have mid-range values of capital productivity. The thrifts in the U.S. (prior to the revision of their regulatory structure) were examples of such concerns. These firms had relatively low levels of capital intensity due to lax regulation. In the absence of adequate oversight, the option of removing the assets and absconding prior to the arrival of the holders of the thrifts' liabilities (depositors) simply proved too great of a temptation. The savings and loans debate that resulted involved the looting of assets in the region of US $\$ 140$ billion (see Akerlof and Romer (1993)).

Firms that operate in region III (in which $\mathrm{V}^{S O}<0, \mathrm{VL}^{\mathrm{L}}>0$ ) undertake activities that have negative net social worth. All other things being equal, an industry with very low levels of capital productivity is a candidate. The classic example of such an industry was the toxic waste disposal business in the U.S. as it was operated prior to the adoption of the Resource Conservation and Recovery Act (RCRA). At time it was the norm (due to the lack of regulation) to operate toxic waste disposal sites with little or no treatment or care. The typical operator of a dump site depended upon the waste containers and local geology to ensure that any liability arising from the dumping of waste occured well in the future. Virtually no capital was required other than the land used as the dumping site, and very frequently this was $m \sim$ leased for the term of the dumping operation. This behaviour and the liabilities it generated almost certainly rendered these operations of negative social value; but the deferral of liabilities and the availability of liquidation in the interim made the operations financially attractive. This is looting at its clearest: the operations existed in 
these forms solely because of the availability of limited liability. It resulted in an estimated 10,000 orphaned waste sites and clean-up costs in excess of US $\$ 140$ billion to date (see Menell (1991)).

\subsection{The importance of sunk capital investments}

The role of sunk capital is similar to but distinct from the role of fixed capital in determining the incentives of firms for looting. Capital is sunk when there is a cost applied to the liquidation of any part of the capital stock. This implies that the capital value is greater in its current use than when transferred to any other. This is distinct from the capital intensity of the firm generally, in that capital intensity merely registers the relative extent to which the firm is vested in fixed capital versus that which is entirely mobile (i.e. labour). Even when the firm is vested in fixed capital, there will be varying degrees to which that firm is able to liquidate its capital stock and/or apply the stock to other purposes. The different degrees to which capital is sunk will be indicative of varying degrees of commitment to the present industry.

A firm characterised such that it lies within Region I in terms of the degree to which its capital is sunk will take decisions concerning liquidation in an optimal fashion. It has too much at stake in respect to its particular industry to treat the issue of liquidation lightly. An excellent example of such a characteristic is tradename based capital. Tradenames are capital items that are representative of the stock of goodwill attaching to the reputation of a firm. These are highly important assets for many firms, often representing a substantial proportion of firm value as indicated by brandname motivated mergers; recently, accounting principles have been revamped in order to allow for the incorporation of such assets within the financial assets of most firms. Such assets are highly illiquid, in that they are valuable only within the context of the firm's current line of operations; there is some but not substantial value in British Airways marketing its own line of food products, for example. Tradenames are highly valuable capital assets, but usually only in connection with the current set of operations. For this reason it would not be anticipated that firms which invest in the development of a tradename would engage in significant amounts of looting; it would not be possible to acquire the value of such an asset via a liquidation strategy. By contrast a firm with a highly liquid capital stock is much more capable of undertaking a hit and run strategy of the nature of looting. For this reason many hazardous waste disposal firms had few assets other than a lease on the land on which they were dumping. They had little that was vested within this industry, nearly all of their assets were able to be applied equally elsewhere. This allowed for maximum liquidity and placed them solidly within Region III regarding their incentives to loot.

\subsection{The Effectiveness of Care Expenditures}

The final factor of importance in determining which incentives will inhere with regard to liquidation is the effectiveness of expenditures on damage avoidance. It is the gap that lies between the time of benefit incurrence and cost incurrence that creates the incentives for looting; this is the reason why industries with liabilities that accumulate over time are especially prone to the phenomenon. If benefits and costs are incurred simultaneously then the decision will concern whether or not to enter the industry, but their separation in time allows for a third option involving entry with the intention of strategically timed exit. 
The relevance of the effectiveness of care expenditures lies in its capacity to transform the one stream of benefits and costs into another; effective care expenditures substitute current (but lower) costs for future (but greater) damages. A highly productive form of care expenditure function will create the incentives for the firm to exercise this option, but will simultaneously remove the option to loot. In the context of toxic waste disposal, it would have been very difficult for firms to mitigate fully the future costliness of these wastes. By their construction chemical wastes must pass through one of three environmental media (organic, water or air) in their process of biodegradation. (Swanson and Vighi, 1998). Inadequate care expenditures in this industry are only effective in isolating channeling and deferring, but not reducing, the ultimate accumulation of these chemicals within these media. Most of the actions taken by toxic waste firms in the past (e.g. plastic or clay lining of pits) were of this nature. These had virtually no mitigative effect, merely creating a larger loophole by extending the gap between benefit and cost incurrence. If, on the other hand, there had been a readily available low-cost method for treating these materials in a manner that actually reduced their ultimate costliness, then these same firms would have been induced to undertake these measures in order to continue in the business.

\section{Policy implications of the incentives for looting}

The policy implications deriving from this analysis are simply stated, and here they are merely described. (See Mason and Swanson 1995 for a fuller policy anlaysis). They concern, initially, the nature of the industries which require regulation and, secondly, the forms of regulation which they require. At the base of our analysis lies the institution of limited liability and the perverse incentives which it induces. In the absence of limited liability neither the judgement proof problem nor the looting problem would exist. Taking the continued existence of limited liability forms of enterprise as a given, then the policy questions concern the creation of new forms of regulatory institutions in order to address the defects created by this other. The first policy question concerns whether the benefits from retaining the former institution justify the costliness of the problems that require the latter. (Hansmann,H. and R. Kraakman 1991).

Assuming that this is the case, the first policy implication concerns the existence of looting as a distinct phenomenon requiring independent regulation. Most often, these subjects have previously been analysed as issues concerning excessive risk-taking by limited liability corporations, and the ultimate responsibility for the uncompensated risks that they create. (Shavell,S. 1986). Our analysis indicates that there is a separate social problem distinct from the problem of excessive risk-taking. Looting is not about risk generation; it is about rent appropriation. The enterprises pursuing looting know that future costs are being generated - it is only the identity of the recipients of those costs that is unknown.

What sorts of regulatory policies does the looting problem require? The analysis here indicates that the two necessary conditions for looting are: limited liability and accumulating liabilities. Any industry in which limited liability is an accepted organisational form and in which there is a gap between the incurrence of benefits and of liabilities is a candidate for looting strategies and should be considered for regulation on this basis. In this context the sufficient conditions for looting to occur have been outlined 
in the previous section: low capital productivity, low levels of sunk capital and low productivity of care expenditure. The presence of such conditions ensure that for a given project the best return lies in the strategic liquidation of assets.

These conditions also indicate the nature of the policies that may be successful in eliminating this costly strategy from the firm's retinue. The first policy to consider is the requirement of mandatory insurance over a lengthy time horizon (e.g. 30-50 years), that must be provided in advance of incorporation and extend beyond liquidation within industries of the necessary nature. Such an approach would substitute immediate (but smaller) payments in lieu of deferred (but greater) damages, and hence remove the necessary condition of non-simultaneity. This is part of the approach adopted in the U.S., which has a 30 year financial responsibility undertaking (usually in the form of insurance) as a prerequisite to the licensing of waste facilities under the Resource Conservation and Recovery Act.

The problem with this approach (as mentioned briefly earlier) is that private insurers are incapable of undertaking the full measures required for the elimination of this loophole. Historically, private insurors have operated via two primary instruments: rates adjusting and co-insurance. Taking the latter first, it is not possible to co-insure an insured no longer in existence, so this instrument is unavailable in the context of endogenous liquidation. In the case of rate adjustment, it is simply not possible (by definition) to make the rate charged high enough to cover the costs of this loophole. To be effective, the insurance premium would have to be so high as to remove all incentives for liquidation from the industry; however, given that extreme moral hazard can result in the near certainty of damages occurring and extremely high damages (in certain industries dealing with chemicals or other technologies with pervasive effect), this would imply the application of a virtually unlimited premium to such industries. Anything less would leave some residual loophole to be exploited by those engaging in the most extreme forms of moral hazard. If insurance is available, looting may occur through the choice of extreme capital structures, irrespective of the parameters used to set the terms of the insurance policy. Therefore, the traditional instruments of the insuror are incapable of addressing the full problem of looting by themselves; one is unavailable and the other has necessarily limited effect.

This indicates that other, more intrusive forms of instruments are necessary for the regulation of this problem. This is one reason why there is a necessary role for the public sector in this arena. Insurance firms are capable of engaging in the casual monitoring of and rate-adjusting for a wide range of activities, but when more intrusive forms of monitoring are required for their effectiveness, then it is important to retain these monitoring functions within the public sphere. This allows for the maintenance of an arbiter over the reasonableness of the monitoring, i.e. the judiciary, and it provides a more general right to intervene in the public interest.

The other reason that public intervention is desirable is that the activities described here more approximate theft than legitimate risk creating activity. The area with which we are concerned is that region in which the activity itself is of negative societal worth (Region III above) but the limited liability loophole renders the activity profitable. It is the set of activities generated solely for the purpose of capturing the rents represented by the 
uncharged for social insurance of limited liability. As in the case of other forms of theft, there is a public good function to be served by means of monitoring and deterring these forms of rent seeking behaviour.

Where should the line fall between the private sphere and the public in the reg ulation of looting? To some extent, this division of responsibilities must remain somewhat arbitrary, as the insurors should be allowed to insure companies' activities and this insurance should extend beyond the point of liquidation (i.e. should flow from the fact of holding insurance at the time that the activities giving rise to future liabilities take place). However, insurors cannot regulate for looting behaviour, and they should not attempt to adjust their rates to regulate for it (because this will deny affordable insurance to legitimate enterprises). Since it is probably not possible to segregate between those liquidations which were endogenous and those which occurred in response to exogenous risks, the only other bases upon which to separate out between private and public functions will be necessarily arbitrary.

One reasonable basis for separation would be time. Looting can only occur in circumstances in which the costliness of activities are separated from their benefits, and deferred into the future. It is reasonable to expect insurors to be able to foresee some forms of deferred costliness, but not all. They are not privy to all of the information within the industry, only the hazard rate of associated industries. One basis for separating out between private and public functions would be to require implicitly that insurors be aware of the deferred risks of enterprises over a given time period, e.g. ten or twenty years after cessation of activities. This would mean that insurors would be given an explicit and limited time horizon over which they must be prepared to manage risks. They would then focus on the problem of monitoring and adjusting for the reasonably anticipated medium term risks of the enterprise. This would seem to be a manageable problem for an industry managing risks on a foundation of historical data. It is a problem that may be solved based upon experiences with associated industries and reasonable inferences based upon the associated technologies.

Firms which are going to choose to liquidate will not insure voluntarily once the full costs of liquidated firms are included in the premium. This is an avoidable cost in the context of a looting strategy. Therefore, the only means by which private insurance is able to perform a function in this area is through the requirement of mandatory insurance for incorporated status. This is the first pillar of the recommended policy for dealing with looting behaviour: Liability insurance with a life extending some (say,10-20) years beyond the event of liquidation should be a requirement for the granting of limited liability status.

It must once again be emphasised that this requirement of mandatory insurance does nothing to prevent looting forms of behaviour. It merely establishes the division of responsibilities for monitoring for these risks. Insurors under such a regime will now include a premium within their policies which will account for anticipated liquidations (even endogenous ones), but opportunists will continue to see that activities that either a) create higher than anticipated costs and benefits; or b) defer costs beyond the policies coverage will generate opportunities for profitable strategic liquidation. In effect, the insuror's premium will establish the parameters around which the new looting forms of behaviour will take shape. It will be important for the insuror to monitor for planned 
liquidation and adjust for those which are clearly risky, otherwise its market will be constrained by excessive premiums. This is a manageable task so long as the time horizon is maintained short enough that the insuror is able to foresee near term risks from historical data and reasonable inferences from associated technologies. The time horizon for long tail risks managed by insurance firms must be maintained short enough so that this is a manageable task given this sort of information base and this range of instruments.

The remainder of the tail of risk incidence must be managed publically. This allows a wider range of instruments for information acquisition, monitoring and management for those industries which are susceptible to looting. In brief, the public sector should manage the residual long tail risks as follows: 1) it should use the conditions identified above as the basis for identifying those industries which are most vulnerable to looting strategies; 2 ) it should then use the wider powers of the state to require continuing information on the crucial parameters of the firms, e.g. information on the assets or the reserves held by the enterprises; and 3) it should also use those powers to require firms to alter those parameters, when it becomes apparent that looting is an optimal strategy.

This means that the state would be monitoring firms in industries with capital structures and technology involvement that renders "hit and run" sorts of strategies available. They could use the wider powers of the state to require information on both the activities being undertaken and the capital structures that are being maintained. If it becomes apparent at some point that the potential damages are far in excess of the capital being maintained, then the state should be able to recognise the potential for looting as an optimal strategy. Then once again the wider powers of the state could make it feasible for the requirement of further capital injections into these firms, in order to maintain some sort of parity of the firm's assets with the damages of which they are capable.

This has been the essence of the banking regulation strategy over the past half century. After the banking collapse of the depression era, the states saw that the entire economy was at risk from bank liquidations and intervened to manage for this risk. They did so by means of ongoing monitoring of operations (independent bank audits) and mandated maintenance of capital assets (reserve requirements). These mechanisms were effective in preventing another collapse of the banking system, until the 1980 s when they were relaxed in the savings and loan industry, almost immediately unleashing the looting epidemic that resulted. The prevention of looting necessitates broader sets of powers than are available to the insurance industry: the monitoring of the firm's capital structure and the power to require minimum levels of capital. These are functions of the public sector.

Therefore, the recommended policy for looting is a combination of private and public sector mechanisms. There should be mandatory liability insurance for incorporation status, applicable for a fixed term of years beyond the event of liquidation. This will leave a residual amount of endogenous liquidation, which is best managed by the state. The state should manage this by, firstly, recognising the structural conditions under which it occurs and monitoring those industries which exhibit those characteristics. Secondly, it should not only monitor but also mandate levels of capital required for continuance within the monitored industries. If a firm moves from an adequate capital structure towards an inadequate one, it should be required to immediately transfer new assets into the ongoing enterprise or cease operations. 
This of course sounds like a lot of public intervention into a wide range of possibly very small enterprises (because most of the most suspect ones would be relatively tiny in size). In fact, the undertakings by the state will be much more limited than might be expected, precisely because of the scale of the monitoring required. This is because the costliness of such public monitoring should be passed onto the industries involved, in the form of an additional premium for engagement in the enterprise. Then these firms with relatively slight capital structures but relatively powerful technologies would be responsible for paying both the mandatory insurance premium (covering the medium tail risks) and the government monitoring supplement and risk premium (covering the long tail risks) in order to procure incorporation status. These charges are going to be excessive for firms with relatively small capital requirements, and they will then elect other forms of organisational structure. They will proceed as partnerships or sole entrepreneurs in those areas in which the costs of incorporation exceed its benefits.

Of course this is precisely what is required. At present the social insurance of limited liability is available to all, those for which this benefit is important (e.g. those requiring large pools of capital) and those for which this benefit is less so. For the latter group, the uncharged for social insurance becomes an opportunity to make use of societal assets while putting little or any of their own on the line. State involvement to monitor and manage capital structures of small corporations is simply the means by which those involved are required to have some of their own assets involved in the enterprise. If they are willing to put their own assets on the line in the first instance (as partnerships and sole owners), then no further governmental involvement is required. In effect, the social insurance subsidy of limited liability should be channelled toward those enterprises requiring it for their existence (primarily the large pools of capital), while the others should be channelled toward other forms of organisation by means of charging them the full cost of their insurance.

\section{Conclusion}

We have discussed the appropriate form that policies must take to address one very specific form of long tail risk problem: the problem of endogenous liquidation in the face of deferred liabilities. This may seem to be a very peculiar part of the overall problem, but it probably is not. Other forms of long tail risks (e.g. the problems of insuring products liabilities where the scale of the risks are unknown) may be successfully managed through insurance futures markets, where the pessimistic insurors reinsure with the more optimistic ones. The problem of long tail risks that cannot be managed completely through any form of private insurance market is the problem of endogenous liquidation. This simply requires too broad of an information base and intervention capacity for private insurors to manage it successfully. The problem of endogenous liquidation requires continuous monitoring for the conditions which make looting profitable (thin capital structures, liquid capital, deferred damages), not monitoring for the existence of damages. Once the damages are occurring (in the context of looting), it is too late; the firms are already liquidated.

Of course there is a role for the private insurance market, but this role must be demarcated in a fashion that will allow them to perform their tasks well based on historical data and reasonable inferences. This implies the necessity of truncating the long tail of liability, at some point some years after liquidation of the firm. The insuror is then 
responsible for monitoring for and managing the risks that occur within this near term time horizon. The purpose of such long tail risk truncation is to make clear the role for the state. The state must then implement a monitoring system for those industries exhibiting characteristics that render liquidation profitable, and it can use its wider powers for the acquisition of broader information on the capital structure of the firm and to manage that same capital structure. This division between private and public sector places the insurance industry in its usual role as risk manager, while the state is performing its customary function as the policeman of anti-social (negative net worth) behaviour.

More importantly, the mere adoption of this system should have the effect of ren dering itself unnecessary. The charges for these insurance mechanisms, private and public, should lie squarely with the firms requiring them. All firms which choose to incorporate should be made to procure mandatory liability insurance commencing upon incorporation and continuing for a fixed term after liquidation. Those firms whose capital structures warrant public scrutiny should be subject to a separate charge, representative of the public costs of monitoring and management, should they elect to incorporate. The conditions which warrant public scrutiny are those firms with limited capital structures but dealing in dangerous sub stances or powerful technologies. Clearly, these firms should be charged the full cost of the social insurance to which they are subscribing when they incorporate, since they represent substantial societal risks while placing few assets of their own on the line. They should also be subjected to a user-fee assessed system of continuous monitoring and capital management. However, once this policy of full cost social insurance is adopted, the relative benefits of incorporation status will be vastly diminished for all firms other than those with requirements of large pools of capital. The smaller enter prises will instead elect to pursue their activities as partnerships and sole enterprises. Then the costliness of the system will be very small, as these large corporations will seldom if ever require the monitoring system that the smaller ones would. In short, the mere creation of a system that is capable of passing through the full cost of social insurance to those responsible for those costs will render that system largely unused.

This is another example of how private markets are unable to operate well in the context of poorly constructed public frameworks. The social insurance subsidy of limited liability creates a framework that renders the private marketing of insurance untenable, because it makes it possible for extreme moral hazard to be profitable. Endogenously created risks cannot be managed by the instruments available to private insurors. For these to be managed the public sector must act to either close this loophole explicitly (by limiting the availability of incorporation status) or implicitly (by charging the full cost of the insurance to the users). Then the private insurance market will be able to return to the task of pooling and managing the remaining risks to society. 


\section{REFERENCES}

AKERLOF, G. A. and ROMER, P. M., (1993): "Looting: The Economic Underworld of Bankruptcy for Profit", Brookings Papers on Economic Activity, 2, 1-60.

BEARD, T. R., (1990): "Bankruptcy and Care Choice", Rand Journal of Economics, 21(4), 626-34.

COOTER, R. D., (1991): "Economic Theories of Legal Liability”, Journal of Economic Perspectives, $5(3), 11-30$.

HANSMANN, H. and KRAAKMAN, R., (1991): "Toward Unlimited Shareholder Liability for Corporate Torts", Yale Law Journal, 100(7), 1897-1934.

MASON, R. and SWANSON, T., 1992, The Geneva Papers on Risk and Insurance Issues and Practice.

MENELL, P. S., (1991): "The Limitations of Legal Institutions for Addressing Envir onmental Risks", Journal of Economic Perspectives, 5(3), 93-113.

POSEY, L. L., (1993): "Limited Liability and Incentives When Firms Can Inflict Damages Greater Than Net Worth", International Review of Law and Economics, 13(3), 325-30.

RINGLEB, A. H. and WIGGINS, S. N., (1990): "Liability and Large-Scale, Long-Term Hazards", Journal of Political Economy, 98(3), 574-595.

ROE, M., (1986): “Corporate Strategic Reaction to Mass Tort”, Virginia Law Review, 72(1), 1-59.

SCHWARTZ, A., (1985): "Products Liability, Corporate Structure, and Bankruptcy: Toxic Substances and the Remote Risk Relationship", Journal of Legal Studies, 14, 689-750.

SEGERSON, K. (1993): "Liability Transfers: An Economic Assessment of Buyer and Lender Liability", Journal of Environmental Economics and Management, 25, S 46-63.

SHAVELL, S. (1986): "The Judgment Proof Problem", International Review of Law and Economics, $6(1), 45-58$.

SIEBERT, H. (1991): "Liability Issues in Pollution Control", in Opschoor, J. B. and D. W. Pearce (eds.), Persistent Pollutants: Economics and Policy, Kluwer Academic Publishers Dordrecht, 183195.

SWANSON, T. and VIGMI, M. (EDS) 1998, The Regulation of Chemical Accumulation in the Environment, Cambridge University Press: Cambridge.

WIGGINS, S. N., and RINGLEB, A. H., (1992): "Adverse Selection and Long Term Hazards: The Choice between Contract and Mandatory Liability Rules", Journal of Legal Studies, 21(1), 189-215. 